\title{
Chemotherapy-induced hypomethylation of N-myc downstream-regulated gene 4 in the bone marrow of patients with acute myeloid leukemia
}

\author{
QINGXIAO HONG $^{1 *}$, XIAOYING CHEN $^{1 *}$, HUADAN YE ${ }^{1}$, XIAODONG WU ${ }^{2}$, \\ XUEJING WANG $^{2}$, LINGYAN KONG ${ }^{2}$, YONGMING XIA ${ }^{2}$ and SHIWEI DUAN ${ }^{1}$ \\ ${ }^{1}$ Zhejiang Provincial Key Laboratory of Pathophysiology, School of Medicine, Ningbo University, Ningbo, \\ Zhejiang 315211; ${ }^{2}$ Department of Hematology, Yuyao People's Hospital, Yuyao, Zhejiang 315400, P.R. China
}

Received July 23, 2015; Accepted September 9, 2016

DOI: $10.3892 / \mathrm{ol} .2017 .5839$

\begin{abstract}
N-myc downstream-regulated gene 4 (NDRG4) has previously been investigated as a possible tumor suppressor. Hypermethylation of tumor suppressor genes contributes to the occurrence and development of certain types of cancer, including acute myeloid leukemia (AML). The current study aimed to assess the contribution of chemotherapy-induced NDRG4 changeable methylation to the development of AML. A total of 30 patients (13 males and 17 females) were involved in the present study. The DNA methylation levels of five C-phosphate-G sites of the NDRG4 gene were measured using bisulfite pyrosequencing techniques. The results indicated significantly reduced gene-body methylation levels of NDRG4 during chemotherapy (prior to chemotherapy: 9.35 $\pm 4.22 \%$; following chemotherapy: $7.54 \pm 3.11 \% ; \mathrm{P}=0.030$ ). Further analysis of AML subtypes revealed the methylation reductions were principally contributed by patients with $\mathrm{M} 2$ subtype AML (prior to chemotherapy: $9.91 \pm 4.76 \%$; following chemotherapy: $5.26 \pm 1.16 \% ; \mathrm{P}=0.038$ ). A significant association was also observed between the patient age and the altered levels of $N D R G 4$ gene-body methylation in patients with $\mathrm{M} 2$
\end{abstract}

Correspondence to: Dr Shiwei Duan, Zhejiang Provincial Key Laboratory of Pathophysiology, School of Medicine, Ningbo University, 818 Fenghua Road, Ningbo, Zhejiang 315211, P.R. China E-mail: duanshiwei@nbu.edu.cn

Dr Yongming Xia, Department of Hematology, Yuyao People's Hospital, 800 Chengdong Road, Yuyao, Zhejiang 315400, P.R. China E-mail: xymfll@163.com

*Contributed equally

Abbreviations: AML, acute myeloid leukemia; NDRG4, N-myc downstream-regulated gene $4 ; \mathrm{CpG}$, cytosine-phosphate-guanine dinucleotide

Key words: acute myeloid leukemia, N-myc downstream-regulated gene 4, DNA methylation subtype AML ( $r=0.761 ; \mathrm{P}=0.047)$, suggesting that reductions in induced-methylation may be age-dependent in patients with M2 subtype AML during chemotherapy. Therefore, age may affect the induced methylation levels of NDRG4 gene-body in patients with AML (particularly patients with M2 subtype AML) during chemotherapy.

\section{Introduction}

Acute myeloid leukemia (AML) is a highly heterogeneous hematologic malignancy, which involves the uncontrolled clonal proliferation of abnormal myeloid progenitor cells in the bone marrow, peripheral blood and other tissues $(1,2)$. The maintenance of hematopoietic cells involves three types of genes, including genes that regulate cell differentiation, the cell cycle and apoptosis (3). Changes in these genes have previously been observed in the occurrence and development of AML (4). Patients with AML have previously benefited from personalized therapy, based on their genetic background (5). Gene hypermethylation may suppress specific gene expression by binding certain proteins to methylated DNA, which induces alterations in chromatin structures and a subsequent decreased affinity for the binding of certain transcriptional factors to methylated C-phosphate- $\mathrm{G}(\mathrm{CpG})$ sites (6). Therefore, the inappropriate silencing of tumor suppressor genes may contribute to cancer tumorigenesis, progression, pathologic grade, invasion and metastasis $(7,8)$. Reversing DNA methylation may improve the sensitivity of leukemia cells to chemotherapy drugs, and may facilitate the development of more effective clinical treatments (9).

$\mathrm{N}$-myc downstream-regulated gene $4(N D R G 4)$ is a member of the N-myc down regulated gene family (9). $N D R G 4$ is a hydrolase involved in modulating cell proliferation, invasion, migration and angiogenesis in certain types of cancer, and it may have a valuable role as a molecular target for novel cancer treatments (10). N-myc overexpression is highly oncogenic in myeloid cells and may contribute to human myeloid leukemogenesis (11), suggesting that the silencing of NDRG4 expression may have a role in the development of AML. 
The aim of the present study was to investigate the methylation status of NDRG4 gene alterations during chemotherapy treatment of AML.

\section{Materials and methods}

Patient and tissue sample collection. Bone marrow samples from 30 patients with AML prior to and following chemotherapy were obtained through bone marrow puncture and collected from the Department of Hematology and Oncology, Yuyao People's Hospital (Ningbo, China) between January 2013 and June 2014. All of the AML cases were assessed at first onset prior to any treatment, and the methylation levels prior to chemotherapy were used as the control. There were 13 male and 17 female patients with a mean age of $47.8 \pm 15.4$ years (range, $19-76$ years), among them; there were 22 patients in remission and 8 patients with poor prognosis. The AML subtype distribution was as follows: three M1, eight M2, seven M3, six M4, three M5 and three M6. The diagnosis of AML was determined in accordance with the revised French-American-British classification system and diagnostic criteria published in $2013(12,13)$. Clinical data, pathological data and chemotherapy regimens were obtained from the medical records and pathology files of the patients, and is described in our previous study (14). The ethical committee of the Yuyao People's Hospital of Ningbo City provided ethical approval for this study. All the patients involved in this study provided written informed consent.

DNA methylation assay. DNA was extracted using the nucleic acid extraction automatic analyzer (Lab-Aid 820; Zeesan Biotech, Xiamen, China) and quantified as described previously using a NanoDrop 1000 spectrophotometer (Thermo Fisher Scientific, Inc., Waltham, MA, USA) (14-16). Genomic DNA was then chemically modified using sodium bisulfite from the EpiTech Bisulfite kit (Qiagen GmbH, Hilden, Germany) as described in our previous study (17). Pyrosequencing was used to evaluate the methylation levels of the cytosines in the amplified DNA fragments, and the pyrosequencing procedure was conducted as previously described (17): The bisulfite modified DNA and NDRG4 primer were mixed and amplified using polymerase chain reaction (PCR). The PCR products were denatured to release the single strands, then the single-stranded DNA template was hybridized to a sequencing primer and sequencing was performed using a PyroMark Q24 system and Gold Q96 reagent (both Qiagen $\mathrm{GmbH}$ ) (17). PyroMark Assay Design software (version 2.0.1.15, Qiagen $\mathrm{GmbH}$ ) was used for primer design. The primer sequences used were as follows: forward, 5'-AGGGTTGGGGGTTTTAGA-3'; reverse, 5'-Biotin-CACCCTCTACCAAAA ACTCAAAAC TCAATT-3'; and sequencing, 5'-GGGGTTTTAGAGTGTAT-3'.

Statistical analysis. The DNA sequences following NDRG4 primer addition were detected. Then the frequency of methylation at specific sites on NDRG4 were analyzed using PyroMark Q24 software (Qiagen, Inc., Valencia, CA, USA). Methylation records of specific sites of $N D R G 4$ in patients with AML were reviewed. The statistical analysis was performed using R software (version 3.1; GNU General Public License; Free Software Foundation, Boston, MA, USA) or SPSS software (version 16.0; SPSS, Inc., Chicago, IL, USA). A paired-sample $t$-test was used to compare NDRG4 methylation levels prior to and following chemotherapy. Wilcoxon signed-rank sum test was used to analyze data that did not have a normal distribution. A Pearson's linear regression analysis was used to determine the association between the mean methylation and patient age, gender, prognosis and AML subtypes. A two-tailed $\mathrm{P}<0.05$ was considered to indicate a statistically significant result.

\section{Results}

NDRG4 CpG sites. As presented in Fig. 1, a total of five $\mathrm{CpG}$ sites were included to represent the methylation of the NDRG4 gene. These five $\mathrm{CpG}$ sites were located in the gene body between exons 1 and 2. The DNA methylation percentages of these five $\mathrm{CpG}$ sites were obtained using a bisulfite pyrosequencing assay on a 63 bp fragment (chr.16:58535416-58535478). The mean methylation levels were used to compare the NDRG4 methylation level alterations in the bone marrow DNA of the patients with AML prior to and following chemotherapy (Fig. 2).

Changes in methylation status of NDRG4 in different subgroups. The results demonstrated a significant reduction in NDRG4 methylation levels in the patients following chemotherapy (prior to chemotherapy, $9.35 \pm 4.22 \%$; following chemotherapy, 7.54 $3.11 \%$; $\mathrm{P}=0.030$; Fig. 2); however, no significant differences were identified between gender and age, and methylation levels prior to, and following chemotherapy. A paired-sample $t$-test of the AML subtypes indicated that patients with M2 subtype AML exhibited a significant reduction of NDRG4 methylation following chemotherapy, compared with patients with other subtypes

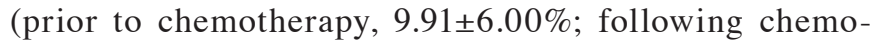
therapy, 5.26 $\pm 2.81 \%$; $\mathrm{P}=0.038$; Fig. 3). As presented in Fig. 4, the association between the NDRG4 methylation changes and patient age was significant for the patients with M2 subtype AML ( $r=0.761 ; P=0.047)$; however, no significant association was observed in the entire patient group $(\mathrm{r}=0.359 ; \mathrm{P}=0.056)$.

Correlation between prognosis and NDRG4 methylation. In addition, the present study investigated the association between prognosis and NDRG4 methylation. The results revealed that the level of chemotherapy-induced methylation changes did not differ between patients with AML in remission and those with a poor prognosis $(\mathrm{P}=0.786$; Fig. 5$)$. Concordantly, this was also observed in patients with M2 subtype AML ( $\mathrm{P}=0.437$; Fig. 5). In addition, $N D R G 4$ methylation prior to chemotherapy was not identified to be associated with patient prognosis $(\mathrm{P}=0.274$; data no shown). Gender-based subgroup analysis revealed that the levels of methylation changes in male patients did not differ from those in female patients (male, $1.83 \pm 3.80 \%$; female, $1.46 \pm 4.12 \%$; $\mathrm{P}=0.806$; data no shown).

\section{Discussion}

In the current study, the NDRG4 methylation level alterations in patients with AML were investigated. The results demonstrated that NDRG4 methylation levels in patients with AML were significantly reduced during chemotherapy, particularly for patients with M2 subtype AML, indicating 


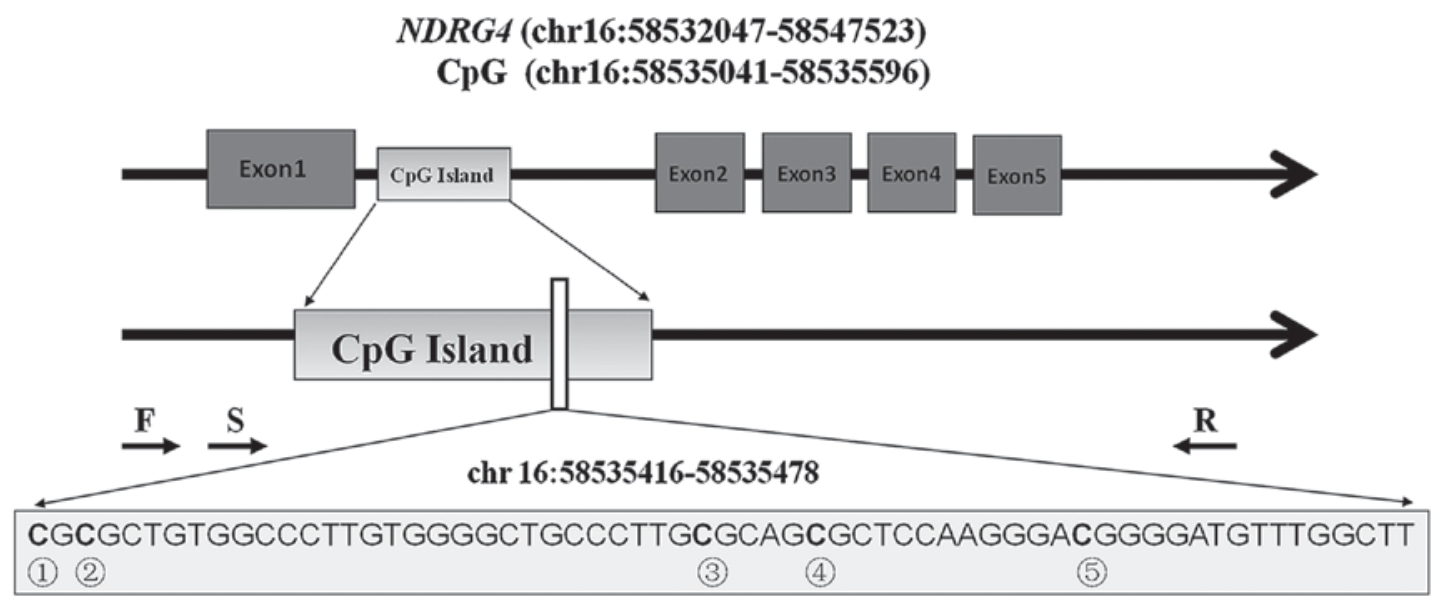

Figure 1. The five investigated $\mathrm{CpG}$ sites information in the $N D R G 4$ gene. $\mathrm{F}$, forward primer; $\mathrm{R}$, reverse primer; $\mathrm{S}$, sequencing primer; Chr, chromosome; $N D R G 4, \mathrm{~N}$-myc downstream-regulated gene 4 ; $\mathrm{CpG}$, cytosine-phosphate-guanine.

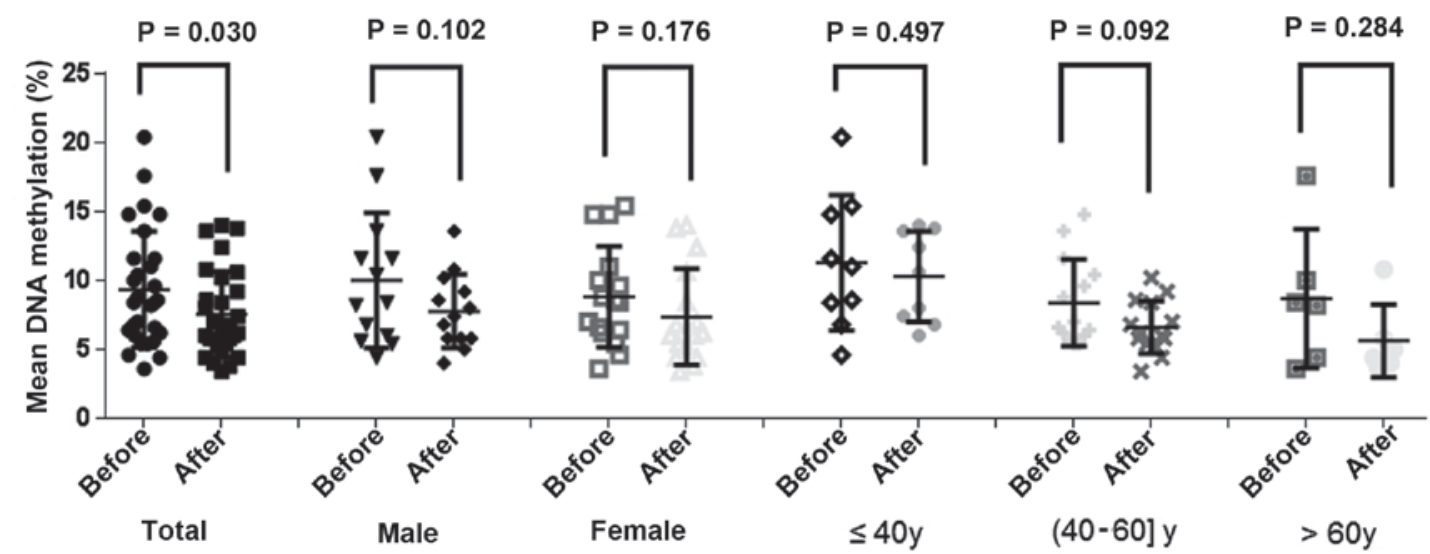

Figure 2. Comparison of the mean N-myc downstream-regulated gene 4 methylation levels prior to and following chemotherapy, by patient age and gender subgroups. Data are represented as the mean \pm standard deviation.

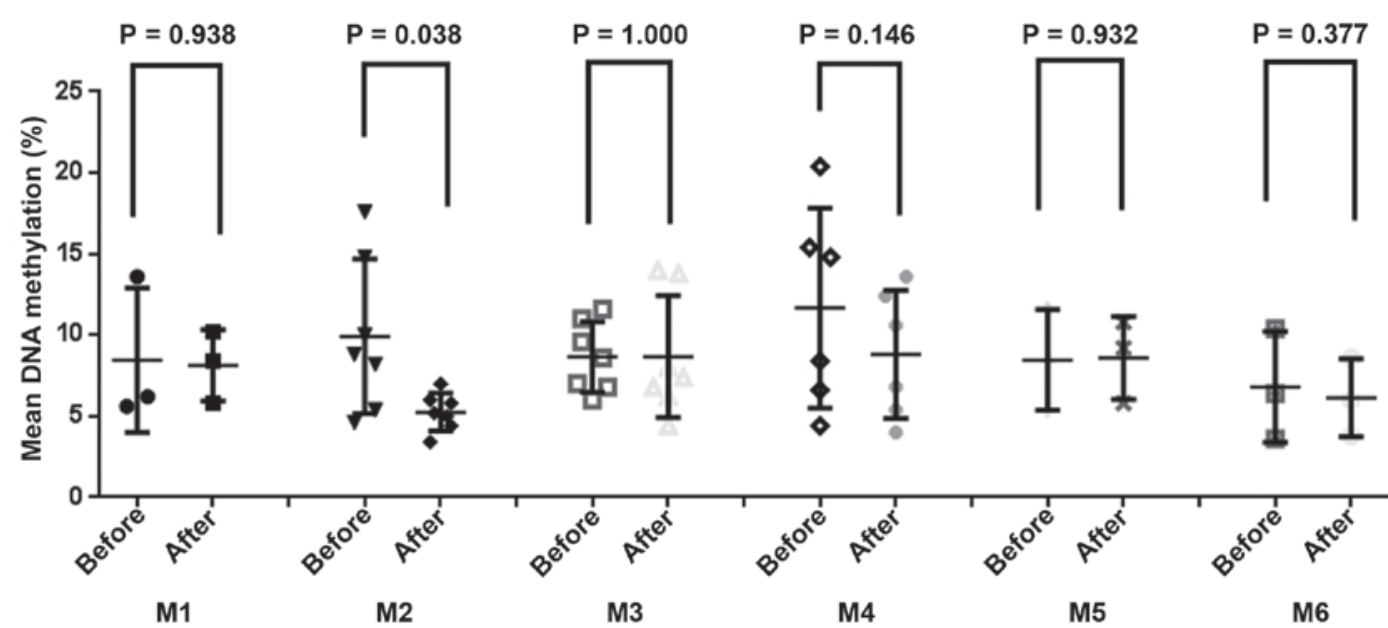

Figure 3. Comparison of the mean N-myc downstream-regulated gene 4 methylation levels prior to and following chemotherapy, based on acute myeloid leukemia subtype. Data are represented as the mean \pm standard deviation.

a chemo-sensitive mechanism underlying NDRG4 methylation. The NDRG4 methylation changes during chemotherapy were positively associated with patient age in patients with M2 subtype AML; further studies are required to fully elucidate the molecular mechanisms underlying the chemotherapy-induced changes observed in M2 subtype AML.

DNA methylation in the gene body has a role in the silencing of genes, and is a therapeutic target of methylation 


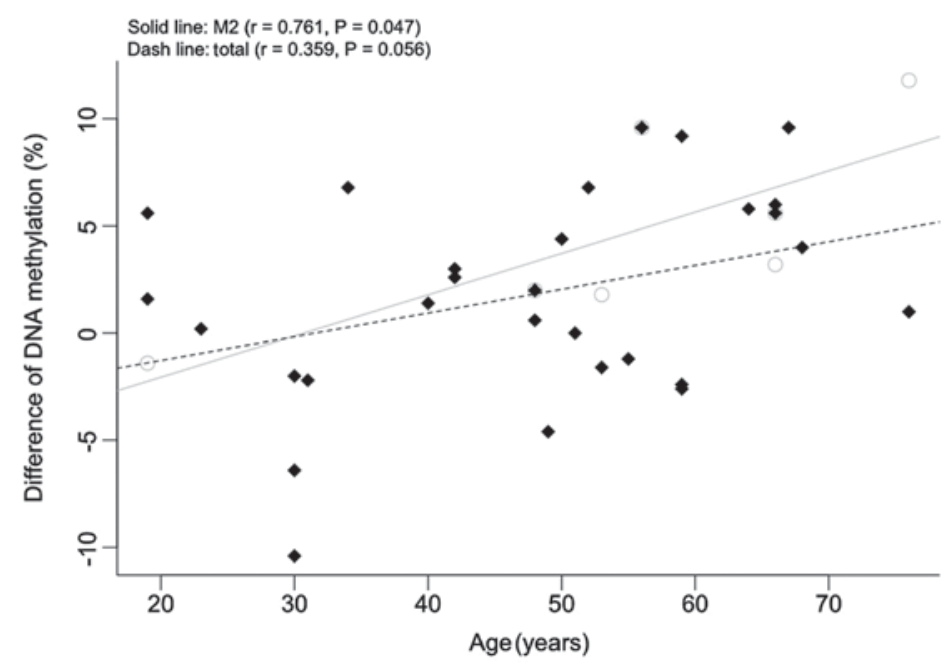

Figure 4. Association between N-myc downstream-regulated gene 4 methylation rate and patient age. The two associations represent the total number of patients with AML (dashed) and patients with the M2 subtype of AML (solid). AML, acute myeloid leukemia.

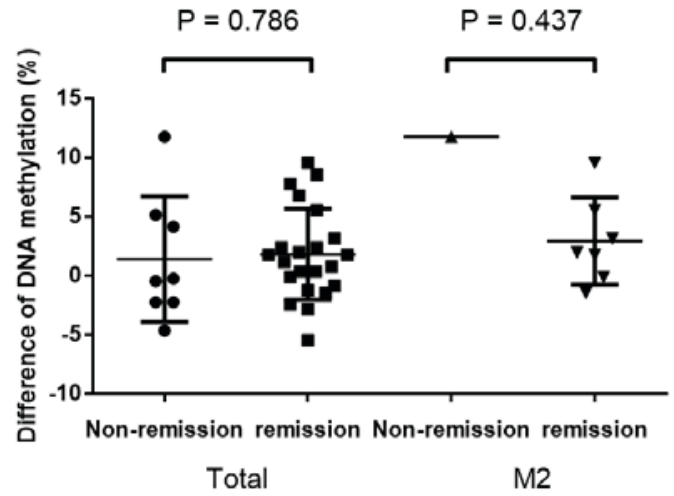

Figure 5. Comparison of the mean N-myc downstream-regulated gene 4 methylation rate between patients with acute myeloid leukemia with remission and non-remission status. Data are represented as the mean \pm standard deviation.

inhibitors (18). Yang et al (18) identified that 5-aza-2'-deoxycytidine treatment reactivated tumor-suppressor genes in addition to decreasing the overexpression of proto-oncogenes. NDRG4 gene-body methylation may improve the sensitivity of a certain type of leukemia cells to chemotherapeutic agents, although the present study did not identify a significant association between the altered levels of NDRG4 methylation and the prognosis of patients with AML, possibly due to the small sample size used.

Cytogenetics is considered a valuable prognostic determinant for AML (19). AML with $t(8 ; 21)(q 22 ; q 22)$ is the most common karyotypic abnormality observed in AML, comprising $\sim 15 \%$ of total cases $(20)$. The incidence of $\mathrm{t}(8 ; 21)$ in $\mathrm{M} 2$ was $24.1 \%$ (21), and it was typically considered to be among the most favorable subtypes for predicting a high response to treatment ( 60\%) (22). The M2 subtype has been frequently associated with additional chromosome abnormalities (23), such as AML/RUNX1 translocation partner 1 fusion gene, which has been detected in $40 \%$ of M2 cases (24) and DEK proto-oncogene-nucleoporin 214 fusion gene, which has been associated with poor prognosis (25). In addition, unique methylation signatures have previously been associated with specific cytogenetic subtypes of AML (26). For example, the spalt like transcription factor 4 hypomethylation rate was demonstrated to be higher in patients with the M1 subtype compared with the M2 and other subtypes (27). p15 methylation has been associated with the M2 subtype (28), whereas the aberrantly methylated BMP/retinoic acid inducible neural specific 1 ( $D B C 1$ ) was observed in cases with nucleophosmin mutations, and fms related tyrosine kinase 3 aberrations were identified to be more prevalent in the methylated $D B C 1$ group (29). In the current study, patients with M2 subtype AML exhibited a significant reduction in NDRG4 methylation levels during chemotherapy. The incidence of AML is frequently associated with increased age, but may occur at any age (30-33). The clinical characteristics of elderly patients with AML differ from those of younger patients, with poorer survival and treatment outcomes (34). Surveillance, epidemiology and end results data demonstrated that the overall 5 -year survival was $<5 \%$ in patients aged $>65$ years of age (35); however, those patients who received high-dose chemotherapy exhibited improved outcomes (34). In the current study, more changeable hypomethylation was observed in elderly patients (particularly patients with M2 subtype AML) than in younger patients, which may facilitate the elucidation of age-associated variations in clinical treatment methods.

There were certain limitations in the present study. The patients enrolled were Chinese individuals from the city of Ningbo; therefore, the significant association between NDRG4 gene-body methylation levels and AML may not be applicable to other ethnic populations. Furthermore, the current study evaluated five $\mathrm{CpG}$ sites, rather than the entire NDRG4 gene region. Therefore, additional $\mathrm{CpG}$ sites must be investigated in further studies. Alternate morphological types have previously been demonstrated to have various effects on AML (36), and the heterogeneity of AML may have influenced the results of the present study. Finally, the conclusions presented were based on a moderate sample size, and therefore further studies using a greater sample size are required to investigate the association between NDRG4 methylation levels and chemotherapeutic outcomes. In conclusion, the results of the present study suggest there may be an age-dependent mechanism underlying the 
induced methylation levels of the NDRG4 gene body in patients with AML, particularly the M2 subtype, during chemotherapy.

\section{Acknowledgements}

This study was supported by the National Natural Science Foundation of China (grant no. 81371469), the Zhejiang Provincial Natural Science Foundation (grant no. LR13H020003), the Ningbo City Medical Science and Technology projects (grant no. 2014A20), the K. C. Wong Magna Fund of the Ningbo University and the Zhejiang Province Student Science and Technology Innovation Plan (grant no. 2015R405081).

\section{References}

1. Estey EH: Acute myeloid leukemia: 2013 update on risk-stratification and management. Am J Hematol 88: 318-327, 2013.

2. Davis AS, Viera AJ and Mead MD: Leukemia: An overview for primary care. Am Fam Physician 89: 731-738, 2014.

3. Yi S, Wen L, He J, Wang Y, Zhao F, Zhao J, Zhao Z, Cui G and Chen Y: Deguelin, a selective silencer of the NPM1 mutant, potentiates apoptosis and induces differentiation in AML cells carrying the NPM1 mutation. Ann Hematol 94: 201-210, 2015.

4. Fang $F$ and Zhu P: Analysis of gene expression profiles to improve the treatment of leukemia. Zhongguo Shi Yan Xue Ye Xue Za Zhi 22: 1735-1738, 2014 (In Chinese).

5. Schlenk RF and Döhner H: Genomic applications in the clinic: Use in treatment paradigm of acute myeloid leukemia. Hematology Am Soc Hematol Educ Program 2013: 324-330, 2013.

6. Pogribny IP, Pogribna M, Christman JK and James SJ: Single-site methylation within the p53 promoter region reduces gene expression in a reporter gene construct: Possible in vivo relevance during tumorigenesis. Cancer Res 60: 588-594, 2000.

7. Ushijima T, Watanabe N, Okochi E, Kaneda A, Sugimura T and Miyamoto K: Fidelity of the methylation pattern and its variation in the genome. Genome Res 13: 868-874, 2003.

8. Jones PA and Baylin SB: The epigenomics of cancer. Cell 128: 683-692, 2007.

9. Itzykson R, Thépot S, Berthon C, Delaunay J, Bouscary D, Cluzeau T, Turlure P, Prébet T, Dartigeas C, Marolleau JP, et al: Azacitidine for the treatment of relapsed and refractory AML in older patients. Leuk Res 39: 124-130, 2015.

10. Tao YF, Xu LX, Lu J, Cao L, Li ZH, Hu SY, Wang NN, Du XJ, Sun LC, Zhao WL, et al: Metallothionein III (MT3) is a putative tumor suppressor gene that is frequently inactivated in pediatric acute myeloid leukemia by promoter hypermethylation. J Transl Med 12: 182, 2014.

11. Kawagoe H, Kandilci A, Kranenburg TA and Grosveld GC: Overexpression of N-Myc rapidly causes acute myeloid leukemia in mice. Cancer Res 67: 10677-10685, 2007.

12. Bennett JM, Catovsky D, Daniel MT, Flandrin G, Galton DA, Gralnick HR and Sultan C: Proposed revised criteria for the classification of acute myeloid leukemia. A report of the French-American-British Cooperative Group. Ann Intern Med 103: 620-625, 1985

13. Fasan A, Alpermann T, Haferlach C, Grossmann V, Roller A, Kohlmann A, Eder C, Kern W, Haferlach T and Schnittger S: Frequency and prognostic impact of CEBPA proximal, distal and core promoter methylation in normal karyotype AML: A study on 623 cases. PLoS One 8: e54365, 2013.

14. Hong Q, Chen X, Ye H, Zhou A, Gao Y, Jiang D, Wu X, Tian B, Chen Y, Wang M, et al: Association between the methylation status of the MGMT promoter in bone marrow specimens and chemotherapy outcomes of patients with acute myeloid leukemia. Oncol Lett 11: 2851-2856, 2016.

15. Huang Y, Ye H, Hong Q, Xu X, Jiang D, Xu L, Dai D, Sun J, Gao X and Duan S: Association of CDKN2BAS polymorphism rs4977574 with coronary heart disease: A case-control study and a meta-analysis. Int J Mol Sci 15: 17478-17492, 2014.

16. Cheng C, Lingyan W, Yi H, Cheng Z, Huadan Y, Xuting X, Leiting X, Meng Y and Shiwei D: Association between TLR2, MTR, MTRR, XPC, TP73, TP53 genetic polymorphisms and gastric cancer: A meta-analysis. Clin Res Hepatol Gastroenterol 38: 346-359, 2014.
17. Tang L, Ye H, Hong Q, Wang L, Wang Q, Wang H, Xu L, Bu S, Zhang L, Cheng J, et al: Elevated $\mathrm{CpG}$ island methylation of GCK gene predicts the risk of type 2 diabetes in Chinese males. Gene 547: 329-333, 2014.

18. Yang X, Han H, De Carvalho DD, Lay FD, Jones PA and Liang G: Gene body methylation can alter gene expression and is a therapeutic target in cancer. Cancer Cell 26: 577-590, 2014.

19. Grimwade D, Walker H, Oliver F, Wheatley K, Harrison C, Harrison G, Rees J, Hann I, Stevens R, Burnett A and Goldstone A: The importance of diagnostic cytogenetics on outcome in AML: Analysis of 1,612 patients entered into the MRC AML 10 trial. The medical research council adult and Children's Leukaemia working parties. Blood 92: 2322-2333, 1998.

20. Cheng CK, Li L, Cheng SH, Ng K, Chan NP, Ip RK, Wong RS, Shing MM, Li CK and Ng MH: Secreted-frizzled related protein 1 is a transcriptional repression target of the $t(8 ; 21)$ fusion protein in acute myeloid leukemia. Blood 118: 6638-6648, 2011.

21. Byun JM, Kim YJ, Yoon HJ, Kim SY, Kim HJ, Yoon J, Min YH, Cheong JW, Park J, Lee JH, et al: Cytogenetic profiles of 2806 patients with acute myeloid leukemia-a retrospective multicenter nationwide study. Ann Hematol 95: 1223-1232, 2016.

22. Nucifora G, Larson RA and Rowley JD: Persistence of the $8 ; 21$ translocation in patients with acute myeloid leukemia type M2 in long-term remission. Blood 82: 712-715, 1993.

23. Shi HX, Jiang B, Qiu JY, Lu XJ, Fu JF, Wang DB and Lu DP: Studies of treatment strategy and prognosis on acute myeloid leukemia with chromosome 8 and 21 translocation. Zhonghua Xue Ye Xue Za Zhi 26: 481-484, 2005 (In Chinese).

24. Hong Q, Ye H, Tang L, Jiang D, Ji H, Dai D, Ouyang G and Duan S: Progress in DNA Methylation Research on Genes Associated with Acute Myeloid Leukemia. Chinese J Cell Biol 37: 299-308, 2015.

25. Servitzoglou M, Grenzelia M, Baka M, Harisi M, Pourtsidis A, Bouhoutsou D, Varvoutsi M, Doganis D, Dana H, Divane A and Kosmidis H: A novel karyotype in acute myeloid leukemia with basophilia. Pediatr Hematol Oncol 31: 149-156, 2014.

26. Ho PA, Kutny MA, Alonzo TA, Gerbing RB, Joaquin J, Raimondi SC, Gamis AS and Meshinchi S: Leukemic mutations in the methylation-associated genes DNMT3A and IDH2 are rare events in pediatric AML: A report from the Children's oncology group. Pediatr Blood Cancer 57: 204-209, 2011.

27. Ma JC, Qian J, Lin J, et al: Aberrant hypomethylation of SALL4 gene is associated with intermediate and poor karyotypes in acute myeloid leukemia. Clin Biochem 46: 304-307, 2013.

28. Chim CS, Wong AS and Kwong YL: Epigenetic inactivation of INK4/CDK/RB cell cycle pathway in acute leukemias. Ann Hematol 82: 738-742, 2003.

29. Alvarez S, Suela J, Valencia A, et al: DNA methylation profiles and their relationship with cytogenetic status in adult acute myeloid leukemia. PLoS One 5: e12197, 2010.

30. Shah A, Andersson TM, Rachet B, Björkholm M and Lambert PC: Survival and cure of acute myeloid leukaemia in England, 1971-2006: A population-based study. Br J Haematol 162: 509-516, 2013.

31. Dores GM, Devesa SS, Curtis RE, Linet MS and Morton LM: Acute leukemia incidence and patient survival among children and adults in the United States, 2001-2007. Blood 119: 34-43, 2012.

32. Bhayat F, Das-Gupta E, Smith C, McKeever T and Hubbard R: The incidence of and mortality from leukaemias in the UK: A general population-based study. BMC Cancer 9: 252, 2009.

33. Australian Institute of Health and Welfare: Cancer survival and prevalence in Australia: Period estimates from 1982 to 2010. Asia Pac J Clin Oncol 9: 29-39, 2013.

34. Yi HG, Lee MH, Kim CS, Hong J, Park J, Lee JH, Han BR, Kim HY, Zang DY, Kim SH, et al: Clinical characteristics and treatment outcome of acute myeloid leukemia in elderly patients in Korea: a retrospective analysis. Blood Res 49: 95-99, 2014.

35. Thein MS, Ershler WB, Jemal A, Yates JW and Baer MR: Outcome of older patients with acute myeloid leukemia: An analysis of SEER data over 3 decades. Cancer 119: 2720-2727, 2013.

36. Gritsaev SV, Martynkevich IS, Ziuzgin IS, Kariagina EV, Martynenko LS, Petrova EV, Tsybakova Nlu, Ivanova MP, Kostroma II, Tiranova SA, et al: Heterogeneity of acute myeloid leukemia with the translocation $\mathrm{t}(8 ; 21)(\mathrm{q} 22 ; \mathrm{q} 22)$. Ter Arkh 86: 45-52, 2014 (In Russian). 